\title{
CONCEPÇÕES DE SURdeZ: A VISÃO DO SURdO QUE SE COMUNICA EM LÍNGUA DE SINAIS ${ }^{1}$
}

\author{
CONCEPTIONS OF DEAFNESS: THE VISION OF THE DEAF PERSON WHO \\ COMMUNICATES IN SIGN LANGUAGE
}

\author{
Mara Aparecida de Castilho LOPES²
}

Lúcia Pereira LEITE ${ }^{3}$

RESUMO: na atualidade, diversas concepções sobre surdez estão presentes na sociedade. Tais concepções, em geral, caracterizam-se pela disputa teórica entre possibilidades comunicativas - oral ou gestual - fundamentadas na importância da apropriação de um código linguístico para o desenvolvimento da linguagem, constitutiva da subjetividade do ser humano. Nesse direcionamento, este estudo objetivou identificar as concepções dos próprios sujeitos surdos a respeito de sua condição. Para coletar os dados da pesquisa utilizou-se um roteiro de entrevista semiestruturado, que foi aplicado a dez participantes surdos, adultos e usuários da Língua Brasileira de Sinais - Libras. As entrevistas foram filmadas, transcritas e submetidas à análise de conteúdo. Os resultados indicam que as concepções de surdez dos surdos constituem uma visão multifacetada sobre essa condição, influenciada pelas relações sociais estabelecidas ao longo de suas trajetórias de vida. Percebeu-se também que o aprendizado da Libras possibilitou aos surdos a própria autoafirmação enquanto ser diferente, com necessidades distintas.

PALAVRAS-CHAVE: Educação Especial. Interação social. Surdez. Linguagem.

ABSTRACT: At this time, diverse views on deafness are present in society. Such views, in general, are characterized by theoretical disputes between communicative possibilities - either oral or gestural - based on the importance of having appropriated oneself of a language code for the development of language, which is essential in the constitution of subjectivity of human beings. Thus, this study aimed to identify the conceptions of deaf people had about their condition. To collect the data we used semi-structured interviews, applied to ten participants who were deaf adult users of the Brazilian Sign Language - Libras. The interviews were taped, transcribed and subjected to content analysis. The results indicate that the conceptions of deafness constitute a multifaceted view on this condition, influenced by social relations throughout each person's life trajectories. The researchers perceived that learning Libras enabled deaf persons to constitute their own assertiveness as someone who is different, with different needs.

KEYWORDS: Special Education. Social interaction. Deafness. Language.

\footnotetext{
${ }^{1} \mathrm{O}$ estudo aqui apresentado é parte da dissertação de mestrado da primeira autora, sob orientação da segunda, e contou com apoio financeiro da Fapesp.

${ }^{2}$ Mestre em Psicologia do Desenvolvimento e Aprendizagem pela Universidade Estadual Paulista - Unesp, campus de Bauru. maracastlo@hotmail.com

${ }^{3}$ Doutora em Educação. Docente do Departamento de Psicologia e do Programa de Pós Graduação em Psicologia do Desenvolvimento e Aprendizagem. Universidade Estadual Paulista - Unesp, campus de Bauru. lucialeite@ fc.unesp.br
} 


\section{INTRODUÇão}

Discussões referentes à concepção de surdez estão presentes na sociedade há muitos anos, caracterizadas pela disputa teórica sobre possibilidades comunicativas, e sucedidas por modos específicos de se perceber a surdez.

$\mathrm{Na}$ atualidade, numa sociedade em constante processo de mudança, a conviç̧ão que permanece, diante de todos os embates teóricos, é que todos os modelos são passíveis de contestação na medida em que podem ser cotejados com a percepção dos sujeitos diretamente envolvidos com o fenômeno estudado.

Retomando brevemente o papel das diferentes modalidades linguísticas, diante das variadas concepções de surdez, observa-se, sumariamente, a existência de duas conjunturas: a defesa do ensino da língua oral, enquanto um meio necessário para a reinserção social dos - então considerados - deficientes; e a língua de sinais enquanto representação de um grupo social minoritário - não mais constituído por sujeitos deficientes, mas diferentes (SKLIAR, 2005).

Em decorrência desses dois posicionamentos, que ao longo dos anos têm-se constituído como antagônicos e mutuamente excludentes, percebeu-se uma relação entre concepção de surdez e comunicação. Após um longo período de disputas teóricas, que perduram até os dias atuais, é constante a provocação de algumas reflexões, tais como: a surdez é uma deficiência ou uma diferença? (BUENO, 1998; SÁ, 2002); a língua de sinais constitui o surdo enquanto sujeito (DIZEU; CAPORALLI, 2005) ou é a apropriação de uma língua - oral ou gestual - que garante a constituição da subjetividade? (SANTANA; BERGAMO, 2007); há apenas duas formas distintas para se compreender a condição de surdez (ROCHA, 2009)?

Frente a tantos questionamentos, é importante considerar que, embora o aspecto linguístico seja fundamental para a compreensão do desenvolvimento do homem enquanto ser social (VIGOTSKI, 1999), para além das especificidades relacionadas à utilização de uma ou outra língua, é necessário primeiramente garantir que o surdo tenha condições de se apropriar de uma língua. Por essa razão, ao considerar que nem sempre as crianças surdas conseguem tornar-se bem sucedidas na aprendizagem da língua oral, a língua de sinais deveria, portanto, ser oferecida como primeira língua à criança surda, buscando-se evitar o atraso no desenvolvimento da linguagem (LACERDA, 2007).

Entretanto, sendo essa uma língua ainda pouco conhecida pela sociedade, as possibilidades interativas dos surdos continuam bastante restritas. Tal aspecto é agravado pelo fato de que a maioria dos surdos tem pais ouvintes (SÁ, 20002), que pouco ou nada conhecem a respeito da língua de sinais.

De um modo geral, a sociedade ainda tem poucas informações a respeito dessa língua, provocando o surgimento de muitos mitos (QUADROS, KARNOPP, 2004). Ao contrário do que muitas pessoas acreditam, as línguas de sinais não são universais, como também não são as línguas orais-auditivas. 
As línguas de sinais igualmente sofrem modificações de um país para outro e mesmo dentro de um único país, de uma região para a outra. No entanto, independentemente da localidade, as línguas de sinais são plenas de todos os aspectos linguísticos, sendo caracterizadas pelo seu aspecto viso-gestual, no qual alguns elementos são de grande importância: o contato visual; a delimitação do espaço no qual os sinais serão efetuados, de modo a serem executados de forma compreensível pelo interlocutor; as condições de iluminação do local onde se pretende efetuar a comunicação; o posicionamento de ambos interlocutores, para favorecer a compreensão de todos os sinais executados por ambas as partes; e o valor das expressões faciais durante a comunicação, que podem transmitir aspectos importantes como intensidade, ironia, desprezo, entre outros. Por essa razão, através da língua de sinais é possível transmitir todo tipo de conteúdo, concreto ou abstrato, nos mais variados gêneros discursivos (BRITO, 1995; FERNANDES, 2003; QUADROS; KARNOPP, 2004; GESSER, 2009).

À luz de tais aspectos, principalmente os linguísticos, que caracterizam os surdos enquanto um grupo social diferenciado, pressupõe-se que a forma como a surdez é percebida pela sociedade ouvinte difere-se do modo como uma pessoa surda analisa a sua própria condição. No entanto, esse fato parece ser pouco estudado nas pesquisas acadêmicas, que, em geral, dedicam-se ao estudo de concepções de surdez de pessoas ouvintes.

Na análise de produções científicas relacionadas ao tema da surdez, foram encontrados estudos que se dedicaram à investigação da concepção de surdez em familiares de crianças surdas, os quais concluíram que essa concepção muitas vezes está relacionada à modalidade linguística utilizada pela criança (SILVA; PEREIRA; ZANOLLI, 2007; BITTENCOURT; MONTAGNOLI, 2007). Porém, ainda que a concepção de pais e familiares possa, de alguma forma, influenciar o modo como a própria criança surda perceberá sua condição de surdez ao longo de sua vida, diversos outros fatores poderão modificar essa visão, como, por exemplo, o sentimento de identificação entre os surdos - que utilizam a mesma língua e compartilham histórias de vida semelhantes, permeadas pelas dificuldades de integração social.

Ao analisar o que descreve Perlin (2005) a respeito da identidade surda, pode-se inferir que esse aspecto está fortemente presente nos movimentos surdos, na consciência de ser diferente e necessitar de recursos visuais para estabelecer a comunicação. A autora ressalta alguns casos específicos em que as identidades surdas se manifestam de formas diferentes: os surdos filhos de pais surdos; os surdos que nasceram ouvintes e se tornaram surdos; os surdos filhos de pais ouvintes, que depois entram em contato com a comunidade surda e com a língua de sinais; os surdos que se percebem como deficientes e nunca chegam a se organizar em comunidades. Destarte, a identidade surda pode ser compreendida como um aspecto que se expressa de variadas formas. 
Ante aos fatores mencionados, é importante examinar a surdez à luz daqueles que se encontram nessa condição. Nessa perspectiva, o estudo aqui descrito objetivou identificar as concepções de surdez apresentadas por sujeitos surdos adultos que se comunicam em língua de sinais, analisando de modo particular os conceitos que o surdo tem de si mesmo, enquanto usuário dessa língua.

\section{MÉtodo}

Os participantes foram dez adultos surdos, sendo cinco homens e cinco mulheres, com idades variando entre 23 e 57 anos, moradores de um município do oeste paulista. Tipos e graus de surdez não foram considerados, uma vez que todos os participantes se comunicavam pela Língua de Sinais Brasileira - Libras.

A coleta dos dados foi realizada em uma sala do Centro de Psicologia Aplicada (CPA - unidade auxiliar da Universidade em que o estudo foi desenvolvido), e o instrumento de coleta utilizado foi um roteiro de entrevista semiestruturado composto de nove questões abertas, abrangendo as seguintes áreas temáticas: concepção de surdez; natureza da deficiência; aprendizagem da Libras; formas de comunicação utilizadas; interação social com ouvintes e surdos.

As entrevistas foram realizadas mediante consentimento prévio dos participantes, firmado no termo de consentimento livre e esclarecido (TCLE) e após a aprovação da realização da pesquisa pelo Comitê de Ética da Universidade (parecer n. 610/46/01/09). Ressalta-se que o roteiro foi aplicado em Libras, pela própria pesquisadora - fluente nessa língua, sendo que cada entrevista foi agendada individualmente com cada participante.

Todas as entrevistas foram posteriormente assistidas e transcritas em Libras, de acordo com os critérios para transcrição utilizados por Quadros e Karnopp (2004). Após esse procedimento, as transcrições dos relatos foram submetidas à análise de conteúdo definida por Bardin (2009). A autora sinaliza que a análise de conteúdo é um conjunto de técnicas de análise de comunicações à luz de procedimentos sistemáticos e objetivos de descrição do conteúdo das mensagens. Tais procedimentos visam obter indicadores (quantitativos ou não) que permitam a inferência de conhecimentos concernentes às mensagens que, neste caso, foram produzidas por meio das perguntas realizadas durante as entrevistas. Há técnicas de análise de conteúdo diversas. Dentre elas, a análise de conteúdo categorial, técnica mais conhecida e que foi a empregada nesta pesquisa. Constitui-se de um procedimento de análise transversal, que recorta das entrevistas temáticas distintas formando uma grelha de categorias extraídas do conjunto do discurso. Optouse por organizar as respostas a partir das questões do roteiro de entrevista, que posteriormente foram reorganizadas, de modo a agrupar nas categorias relatos que apresentassem semelhanças em seu conteúdo. Desse modo, chegou-se a três eixos principais, que procuraram desvelar as concepções dos participantes sobre surdez, relacionamento social e comunicação. 
Na tentativa de assegurar a fidedignidade da transcrição, solicitou-se a colaboração de dois juízes: um surdo - fluente em Libras e um ouvinte - tradutor/ intérprete de Libras. O juiz surdo recebeu a filmagem da coleta realizada com um dos participantes para que a transcrevesse, em Libras, de acordo com os critérios de Quadros e Karnopp (2004).

A transcrição realizada pelo juiz surdo foi enviada para o segundo juiz - ouvinte e conhecedor da Libras - juntamente com a transcrição realizada pela pesquisadora, referente à coleta do mesmo participante. Esse juiz recebeu a orientação de analisar as duas transcrições, verificando a concordância entre as intenções verbais expressas em cada frase, em cada uma das transcrições. Esse procedimento indicou um índice de $89 \%$ de concordância entre as duas transcrições, sendo então consideradas pertinentes as transcrições realizadas.

\section{Resultados E Discussão}

Como relatado anteriormente, a análise dos relatos coletados durante a entrevista foi realizada pela categorização das falas dos participantes que foram dispostas em três grandes eixos: 1) Concepções sobre surdez: percepções e sentimentos; 2) Surdez e relacionamentos sociais: identificação grupal e interações sociais; 3) Surdez e comunicação.

O quadro a seguir apresenta a organização das falas dos participantes por eixo de análise e categorias de respostas:

Quadro 1: Eixos de categorias organizadas a partir das falas dos participantes

\begin{tabular}{|l|l|l|}
\hline \multirow{2}{*}{ Eixos } & \multicolumn{2}{|c|}{ Categorias de respostas apresentadas } \\
\hline \multirow{2}{*}{$\begin{array}{l}\text { Eixo 1: concepções de surdez: } \\
\text { percepções e sentimentos }\end{array}$} & Percepções & Igualdade \\
\cline { 2 - 3 } & \multirow{2}{*}{ Sentimentos } & Desvantagem \\
\cline { 2 - 3 } & & Tristeza/piedade/desprezo \\
\cline { 2 - 3 } $\begin{array}{l}\text { Eixo 2: surdez e relacionamentos } \\
\text { sociais }\end{array}$ & Identificação com pares igualmente surdos \\
\cline { 2 - 3 } & Interações sociais com surdos e ouvintes \\
\hline \multirow{2}{*}{ Eixo 3: surdez e comunicação } & Leitura labial \\
\cline { 2 - 3 } & Escrita \\
\hline
\end{tabular}

\subsection{EIxo 1: ConCEPÇÕES DE SURDEZ: PERCEPÇões E SENTIMENTOS}

O Eixo 1 abrange as falas em que os participantes descreveram o que pensam sobre a surdez, à luz de suas experiência de vida, narrando também os sentimentos envolvidos e as diversas percepções que possuem da surdez e de si mesmos. 
Tendo o ouvinte como referencial, as percepções sobre a surdez dividiramse em igualdade ou desvantagem. Os sentimentos também apareceram de duas maneiras: de forma negativa, relacionados à tristeza, piedade ou desprezo; ou de forma positiva, relacionados à felicidade ou sensação de igualdade.

Dos dez participantes entrevistados, seis descreveram a surdez a partir de uma condição de desvantagem perante o ouvinte. Essa percepção esteve fundada na comunicação ou na sua ausência, salientando algumas situações específicas, tais como a dificuldade de escolarização do surdo, ou ainda, a dificuldade em compreender informações transmitidas em ambiente de trabalho, que, em geral, são transmitidas apenas pela modalidade oral. A fala de uma participante, Sílvia4, exemplifica tal situação:

$$
\text { É difícil estudar... para o ouvinte é fácil, mas para o (a) surdo (a) é difícil. }
$$

Em situação oposta, quatro participantes situaram a surdez em uma posição de igualdade ao ouvinte, descrevendo a surdez como uma condição normal, fundamentados em aspectos que consideram positivos, como o suporte do grupo social formado pelos surdos - a comunidade surda:

Fábio: Deus ajuda todos, ouvintes... normal (...). Também há muitos outros surdos, normal... (...) é bom, existe união, amizade, conversas normais entre surdos e ouvintes, em Libras, é normal, somos iguais, surdos e ouvintes são iguais.

Com relação aos sentimentos relacionados à surdez, as falas dos participantes se apresentaram de duas formas: uma que indicava como o participante se sentia, à luz da sua condição, e como percebia a visão do ouvinte com relação aos surdos em geral. Nessas falas, puderam ser identificadas duas subcategorias, uma compreendendo as respostas que envolviam sentimentos relacionados à tristeza, piedade ou desprezo, e outra compreendendo sentimentos de alegria/ felicidade. Nas duas subcategorias observou-se novamente o sentimento de igualdade ou diferença em relação ao ouvinte.

Nesse contexto, observou-se que os sentimentos de tristeza, piedade ou desprezo foram recorrentes nas falas dos participantes:

\footnotetext{
Alexandre: Eu sou triste... eu queria... queria ouvir, Deus sabe o quanto.

Thomas: Ser surdo é difícil, eu não tenho amigos, fico sozinho, as pessoas não conhecem a surdez...
}

Ao falar das relações estabelecidas em seu local de trabalho, Luana expõe uma situação que lhe causa muito aborrecimento, o isolamento resultante da barreira comunicativa entre ela e seus colegas: 
Luana: ...Lá é difícil, eu sempre digo que gostaria que fossem mais surdos para lá, aí eu ficaria feliz, poderia conversar com alguém em Libras, seria melhor, com os ouvintes não há comunicação, é ruim... me faltam amigos... eu preciso de amigos...

Ao expressar o desejo de que outros surdos fossem contratados, é visível que suas intenções estão voltadas à questão da comunicação, que não ocorre com os atuais colegas ouvintes. Ressalta-se então que a identificação entre os surdos pode ser entendida como elemento de grande importância para a compreensão das relações sociais estabelecidas dentro da comunidade surda, cabendo questionar se a forma como essas relações intergrupo ocorrem poderia ser modificada se a sociedade - predominantemente ouvinte - tivesse maior interesse no aprendizado e no uso da Libras.

A resposta a esse questionamento parece ser afirmativa, ao observar o posicionamento de Luana sobre sua relação com os antigos colegas de escola ouvintes e o de Roberto em relação ao modo como sente que os ouvintes o percebem, enquanto surdo:

Luana: Antes eu estudava com uma turma que já estava acostumada com a Libras, pois crescemos juntos, eles estavam acostumados, conheciam a Libras, era normal.

Roberto: As pessoas me olham, pessoas que eu não conheço, me olham (...) não gostam de mim, me ofendem...

O modo como um sujeito percebe o outro pode influenciar o modo como ele percebe a si mesmo (HINDE, 1997). Nessa compreensão, a percepção do desprezo de algumas pessoas ouvintes pode influenciar a concepção do surdo sobre sua própria condição, fazendo com que ele se considere inferior. Dessa forma, a língua de sinais, enquanto elemento característico dessa condição, pode ser desvalorizada até mesmo pelo sujeito surdo que a utiliza, aspecto que parece estar refletido na fala do participante Mário, ao descrever o que os ouvintes pensam sobre os surdos, em sua opinião:

Mário: Não gostam... se o surdo souber falar (oralmente), gostam mais ou menos... eu falo um pouco...

Muitos dos surdos que utilizam a língua de sinais na fase adulta, já passaram pela reabilitação oral em algum momento de sua trajetória, recorrendo à língua de sinais como alternativa de comunicação diante da impossibilidade de desenvolvimento da oralidade. A língua de sinais pode ser então percebida pelo surdo como uma língua inferior à língua oral, e pode, nessa condição, ser percebida negativamente, como um aspecto discriminativo da pessoa surda que não conseguiu desenvolver a oralidade. 
Isso parece ser considerado pelo participante Mário, que percebe a valorização da comunicação oral, além de responsabilizar o próprio surdo pelo fracasso da comunicação com o ouvinte, justificando seu desprezo pelo surdo.

Além do desprezo, alguns participantes também descreveram sentimentos relacionados à piedade dos ouvintes perante os surdos, conforme se observa na fala de Júlia:

Júlia: "Você é surda? Coitada..." (...) Na escola, como me ensinariam? Era difícil, eu não entendia... eu ficava triste, parecia triste... escrevia quieta... uma colega via e dizia: “Coitada, é surda... você quer que eu te ensine?", eu dizia: “Quero", ela me ensinava e aí eu aprendia.

Os sentimentos de piedade apontados, em geral relacionaram-se a situações de âmbito escolar, que ainda constituem uma situação de grande desvantagem para o aluno surdo, visto que apenas recentemente o sistema escolar começou a considerar a necessidade de profissionais da Libras nesse ambiente e a possibilidade da inserção do intérprete no espaço escolar (BRASIL, 2005).

No entanto, a situação do surdo continua bastante prejudicada pela baixa demanda de intérpretes de Libras e professores com conhecimento operacional nessa língua, além do escasso domínio da língua de sinais por parte dos alunos ouvintes, fatos que prejudicam o acesso do aluno surdo aos conteúdos acadêmicos e as suas possibilidades de interação social nesse meio e, consequentemente, de seu desenvolvimento.

\subsection{EIXo 2: SURDEZ E RELACIONAMENTOS SOCIAIS}

O Eixo 2 abrange as falas que envolvem uma concepção interacionista sobre a surdez (OLIVEIRA, 2004). Nesse Eixo, foram compreendidas duas categorias de resposta: percepção da surdez a partir da identificação com pares igualmente surdos e percepção da surdez no contexto das interações sociais estabelecidas, com surdos e com ouvintes.

A percepção dos participantes sobre os relacionamentos sociais foi analisada a partir de dois conjuntos das falas: as que indicassem relações sociais estabelecidas somente com outros surdos; e as que mencionassem relações sociais com segmentos não específicos - com surdos e com ouvintes. Considerou-se como relação circunstâncias descritas pelos participantes que envolvessem algum tipo de interação intermitente entre duas pessoas, durante determinado período, (HINDE, 1976; 1997), compreendendo que tais aspectos são influenciados pelo contexto cultural em que se inserem os sujeitos em questão.

A identificação entre os surdos é um aspecto bastante recorrente nos estudos teóricos da área da surdez, nos quais surge frequentemente associada à língua de sinais. No entanto, conforme apontou Perlin (2005), a identidade surda se manifesta de formas variadas, assim como a língua oral, e pode constituir a 
identidade do surdo, pois o que garante a construção de sua subjetividade é a apropriação de uma língua e não sua natureza oral ou gestual (SANTANA; BERGAMO, 2005). Igualmente, um surdo que faz uso concomitante da língua oral e de sinais poderia ser um membro atuante da comunidade surda, o que reforça a ideia de que a identificação entre os surdos está além do aspecto linguístico.

Porém, considerando a convivência simultânea com as duas comunidades, surda e ouvinte, a língua de sinais é um elemento de grande influência na identificação do sujeito com o grupo surdo:

Luana: Se eu estiver passeando junto com minha mãe, minha família, as pessoas me olham, eu sinto vergonha. (...) Sozinha eu sinto vergonha, é verdade... minha mãe não entende, é diferente... difícil. Quando falo em Libras, as pessoas me olham, riem (...). Com o grupo surdo, combina, quando os surdos estão em grupo, conversando em Libras, as pessoas também olham, entende? Mas é diferente, eu sinto.

A participante Luana também descreve o grupo de amigos surdos como um apoio, pois estando com seus pares linguísticos não sente vergonha em se comunicar em Libras, ao contrário de quando está sozinha com sua família ouvinte.

Marchesi (1995) afirma que a possibilidade de realizar atividades com o grupo de pessoas que compartilham os mesmos problemas é um fator determinante para uma avaliação positiva das possibilidades de relacionamento social.

Esse ponto de vista também parece se confirmar na fala do participante Thomas, o qual demonstra uma visão de surdez a partir de sua representatividade enquanto grupo minoritário, que de alguma forma esteja ameaçado, o que justificaria sua preocupação com a união desse grupo:

Thomas: Se eu não conheço (o surdo), digo: "Muito prazer", o convido, é necessário... eu penso, se o surdo mora longe, por exemplo, mesmo que eu não o conheça, é importante manter a união, somos da mesma carne, é importante, nós surdos somos como irmãos da mesma carne. Precisamos estar juntos, unidos, sermos amigos.

Ao referir-se aos surdos como 'irmãos da mesma carne', é possível perceber nessa fala a manifestação de um discurso veiculado por alguns grupos e movimentos surdos, consolidado por muitas pesquisas acadêmicas, que defende a ideia de que os surdos apresentam algum tipo de uniformidade coletiva, decorrente de seus maiores atributos próprios, a saber, a identidade e a cultura surdas (GESSER, 2009).

Diante de tais termos, ignora-se a cultura do grupo social dentro do qual os surdos estão inseridos, partilhada por todos os membros do grupo que ali vivem - surdos ou ouvintes - para defender a existência de uma cultura própria do surdo. Nesse aspecto, cabe aqui apresentar concordância com o que afirma Gesser (2009) ao argumentar que ao termo "cultura" é aqui empregado num sentido distintivo, que sugere a necessidade de visibilidade de um grupo social que clama por reconhecimento e valorização. 
Da mesma forma, ressalta-se o conceito de que os surdos representam um grupo homogeneamente constituído, dentro do qual as outras identidades - como gênero, etnia ou nacionalidade - parecem ser anuladas diante da identidade surda (SANTANA; BERGAMO, 2005). No entanto, isso nem sempre ocorre, conforme se observou na fala de outro participante, Mário. Ao ser questionado sobre suas preferências de relacionamentos, ele afirma que não gosta de interagir com os surdos:

Mário: Com surdos não. Com os surdos eu parei, eu gosto de educação, sempre, com bagunça é difícil (...) com os que falam (os ouvintes) eu vou passear junto, sempre (...), eu sou velho, tenho 57 anos, não tenho mais $19 .$.

Considerando que Mário era o único participante com idade discrepante dos demais, cuja média excetuando esse participante era de 25 anos, sua fala sugere a ausência de identificação com um grupo específico de surdos, mais jovens. Ou seja, a identificação por faixa etária, nesse caso, pareceu sobressair-se à identificação pela surdez.

Falas que descrevem situações de interação com outros surdos apareceram com grande frequência, sendo que todas elas estavam relacionadas a situações de lazer, em especial com amigos ou familiares surdos, conforme se percebe no relato de Roberto: Quando meu irmão chama algum amigo ouvinte, nós vamos separados, eu sempre vou com os surdos (...) vamos ao cinema, passear, eu gosto de ir ao cinema, é divertido.

Apenas dois participantes descreveram também interações estabelecidas com pessoas ouvintes, que pode ser retratada no relato:

Thomas: É importante estar em grupo, ir à casa de amigos, passear juntos (...), em Libras, ou pela leitura labial, eu posso rir, conversar (...) é igual com o ouvinte, a amizade é igual (...), eu não posso me afastar dos ouvintes, porque são amigos (...) não é igual, é diferente, são coisas separadas.

A diferença mencionada por Thomas durante seu relato parece estar relacionada a elementos particulares que o aproximam do grupo constituído pela comunidade surda, que nesse caso se expressa pela língua de sinais e pela própria condição de surdez. Porém, o fato de também poder se comunicar através da leitura orofacial lhe permite desenvolver relacionamentos também com pessoas ouvintes.

\subsection{EIXo 3: SURDEZ E COMUNICAÇÃO}

O Eixo 3 abrange os relatos que descrevem a surdez em sua relação com a forma de comunicação utilizada pela pessoa surda, ou seja, estaria relacionada a uma concepção psicossocial da surdez (OLIVEIRA, 2004), na qual o aspecto linguístico surgiu como o fator mais representativo.

Frente às informações relativas à idade em que os participantes tiveram acesso a Libras, observou-se que mesmo aqueles que tinham outros surdos na 
família tiveram contato tardio com essa língua. Porém, chegando à fase adulta, todos os surdos pesquisados neste estudo tinham considerável fluência na Libras, destacando-se aqui a importância dos contatos intragrupo, estabelecidos no contexto da comunidade surda, para o desenvolvimento linguístico de seus membros. Como aponta Perlin (2005, p. 63): "o adulto surdo, nos encontros com outros surdos, ou melhor, nos movimentos surdos, é levado a agir intensamente e, em contato com outros surdos, ele vai construir sua identidade fortemente centrada no ser surdo, a identidade política surda". Outrossim, as interações entre os surdos em tais ambientes é de extrema necessidade, uma vez que dentro do núcleo familiar os processos interativos são dificultados, conforme se observa no relato do participante Fábio, que possui irmãos surdos:

Com os meus irmãos, a comunicação em Libras é boa. Meu pai não entende, nem minha mãe ouvinte, todos os familiares ouvintes não entendem a Libras.

Nesse aspecto evidencia-se uma realidade presente no cotidiano de muitos surdos que se comunicam em língua de sinais - as dificuldades comunicativas, que se iniciam já no ambiente familiar, posteriormente se estendem ao resto da sociedade ouvinte. Entretanto, também é preciso considerar aquelas situações em que a família da criança surda não conhece a Libras, que somente é apresentada aos familiares como última alternativa para se comunicar com o filho surdo $\square$ resultando na desvalorização dessa língua ou no sentimento de fracasso em desenvolver a comunicação oral.

Porém, espera-se que essa concepção familiar possa ser modificada com o passar do tempo, na medida em que a criança surda vai crescendo e se desenvolvendo com o uso de uma língua que lhe permitiu seu desenvolvimento, constituindo sua própria subjetividade.

No entanto, mesmo um surdo que utiliza a língua oral poderia se interessar pela Libras, visto que os critérios de participação nas comunidades surdas são de natureza social e não decorrente somente de aspectos biológicos (GÓES, 1999). O participante Thomas sinalizou isso quando afirmou realizar leitura orofacial com pessoas ouvintes, mas na interação com os surdos valoriza a Libras como língua oficial:

Thomas: Com a família eu tento falar... porque eles não entendem Libras. Mas também, com os amigos surdos, eu sempre uso a Libras (cerra os lábios como quem está evitando falar) sempre Libras.

Além disso, durante a entrevista com a pesquisadora - ouvinte - ainda que todo o procedimento tenha sido mediado pela Libras, Thomas sempre procurava se comunicar oralmente com concomitância dos sinais da Libras, misturando as estruturas gramaticais das duas línguas. Contudo, esse fato não parecia ser ignorado por ele, pois quando afirma que utiliza a Libras com os amigos surdos, esse participante procurava cerrar os lábios, demonstrando que na comunicação 
com outros surdos não há necessidade de comunicação oral por nenhum dos interlocutores.

Por esse aspecto, compreendeu-se a existência de uma concepção de que entre os surdos a comunicação ocorre de maneira mais livre, como se as interações com os ouvintes sempre estivessem carregadas de expectativas de que o surdo fale oralmente, ou de constante preocupação em se fazer entender pelo ouvinte, que, em geral, não domina Libras.

Ainda, outros aspectos também foram mencionados pelos participantes para auxiliar na comunicação, como a importância do intérprete de Libras para a melhoria das interações entre o surdo e a sociedade ouvinte, fato relatado por Luana ao apontar suas dificuldades no ambiente de trabalho, durante situações de reunião:

Luana: Há uma lei sobre o intérprete de Libras, é necessário. Nas cidades ao redor tem, mas aqui falta. É difícil, paciência. Eu leio as projeções, mas tenho preguiça, em Libras é melhor. Quando eu leio, não entendo bem as palavras em Português, é difícil. Eu fico quieta... é difícil (...). Quando tem algum teste, é difícil. Nas reuniões... quando vão mostrar o que não pode fazer, eu leio...

Marin e Góes (2006) reforçam a questão das barreiras linguísticas entre surdos e ouvintes em local de trabalho, ressaltando que nas instituições onde há funcionários surdos, as explicações e as regras anunciadas pela chefia são transmitidas, em geral, unicamente pela modalidade oral. Entende-se que a discussão sobre a presença do intérprete nesses ambientes consiste em uma necessidade urgente, principalmente em função das dificuldades de integração que os surdos sofrem devido à falta de comunicação com os colegas, tanto em situações de trabalho, quanto nas situações em ambiente escolar, impossibilitando-os assim de participar ativamente de várias instâncias sociais que qualificam o sujeito.

A valorização da língua oral pelos surdos somente se deu em situações nas quais o interlocutor é ouvinte, fato apontado por quatro entre os dez participantes:

Thomas: Com a família só uso a leitura labial porque eles não entendem Libras (...). A comunicação oral é importante para estudar, entende... é necessário fazer a terapia fonoaudiológica, entende, para estudar, entender sempre, eu também uso o AASI porque quero ouvir...

Além disso, a língua escrita também foi apontada pelos participantes como um recurso comunicativo, na impossibilidade do interlocutor compreender a língua de sinais, fato relatado por seis participantes, como esse exemplo:

Alexandre : Eu escrevo e mostro... pouco, eu não entendo tudo não, só um pouco.

Ainda que no presente estudo não se pretenda tratar sobre as possibilidades de aquisição da língua escrita por sujeitos surdos, ressalta-se aqui, pela análise das falas dos participantes parece ser difícil tal aquisição. Entretanto, a compreensão da escrita também foi apontada como uma tentativa de remediar um problema 
maior - as dificuldades de interação com as pessoas ouvintes, que pouco utilizam a língua de sinais.

\section{Conclusões}

Diante dos resultados obtidos com o estudo aqui apresentado, evidenciase o fato de que as diferentes visões sobre a condição de surdez estão muito além das discussões dualistas sobre formas de comunicação - oral e gestual, que podem ser observadas nos mais diversos ambientes sociais, inclusive que permeiam a produção científica. De imediato, a complexidade que caracteriza as várias concepções de surdez presentes na sociedade se traduz na quebra de uma visão dualista para transformar-se aqui em multifacetada, superando as argumentações teóricas que partem em defesa de um modelo a ser seguido.

Neste texto, os participantes descreveram a surdez a partir da própria trajetória de vida, na qual a comunicação perpassa todas as formas de reabilitação. A língua preferencial foi a Libras, porém alguns relatam utilizar rudimentarmente outras formas de comunicação em função da necessidade comunicativa, em especial com os ouvintes.

Este estudo acredita que a própria participação dos surdos na pesquisa acadêmica surge como um diferencial, considerando que são os principais interessados com relação ao que se discute na temática da surdez, assim como também devem ser beneficiados com os resultados de qualquer produção científica realizada sobre a temática. Com isso traduz-se a necessidade que tais pesquisas ampliem a sua divulgação a comunidade surda.

$\mathrm{Na}$ realidade analisada, observou-se que o aprendizado da Libras possibilitou aos surdos a própria autoafirmação enquanto ser diferente, com necessidades distintas que devem ser respeitadas e exigidas, visto que estão garantidas pelas normativas legais.

Por outro lado, identificou-se também a necessidade de que a língua de sinais seja mais valorizada, inclusive nos ambientes familiares nos quais os surdos estão inseridos. Sem desconsiderar a complexidade da Libras e o esforço necessário para o seu aprendizado - fato semelhante com o aprendizado de qualquer outra língua - caberia também refletir sobre a importância de minimizar as distâncias comunicativas entre pessoas de um mesmo núcleo familiar, para possibilitar o estabelecimento do vínculo e viabilizar formas de desenvolvimento humano.

Por fim, caberia a toda a sociedade refletir sobre os procedimentos necessários para viabilizar a inclusão do surdo. Muito se avançou quando se reconhece a Libras, como língua oficial brasileira (BRASIL, 2002), prevista nas normativas legais. Entretanto, a sua oferta e disseminação ainda estão longe de ocuparem as instâncias sociais, de saúde, trabalho, de lazer, entre outras, se restringindo em grande parte a poucos estabelecimentos educacionais ou a locais específicos que atendam a essa demanda populacional, como clínicas ou 
instituições de reabilitação, por exemplo. $\mathrm{O}$ fomentar de pesquisas na área e a ações que viabilizem que prescrições legais possam ser realmente efetivadas, como no caso disponibilidade de intérprete, ensino da Libras nas escolas, entre outras, certamente promoverão oportunidades de que sujeitos surdos possam participar mais ativamente da sociedade.

\section{REFERÊNCIAS}

BARDIN, L. Análise de conteúdo. Lisboa: Edições 70, 2009.

BITTENCOURT, Z. L. C.; MONTAGNOLI, A. P. Representações sociais da surdez. Medicina, Ribeirão Preto, v.2, n.40, p.243-249, 2007.

BRASIL. Decreto n. 5.626, de 22 de dezembro de 2005. Regulamenta a Lei n. 10.436, de 24 de abril de 2002. Dispõe sobre Língua Brasileira de Sinais - Libras, e o art. 18 da Lei n. 10.098, de 19 de dezembro de 2000. Diário Oficial[da] República Federativa do Brasil, Brasília, DF.

. Lei n. 10.436, de 24 de abril de 2002. Dispõe sobre a Língua Brasileira de Sinais Libras e dá outras providências. Diário Oficial [da] República Federativa do Brasil, Brasília, DF.

BRITO, L. F. Por uma gramática da língua de sinais. Rio de Janeiro: Tempo Brasileiro, 1995.

BUENO, J. G. S. Surdez, linguagem e cultura. Cad. Cedes, Campinas v.19, n.46, p.7$15,1998$.

DIZEU, L. C. T. B.; CAPORALLI, S. A. A língua de sinais constituindo o surdo como sujeito. Educ. Soc., Campinas, v. 26, n. 91, p. 583-597, 2005.

FERNANDES, E. Linguagem e surdez. Porto Alegre: Artmed, 2003.

GESSER, A. Libras?: que língua é essa?: crenças e preconceitos em torno da língua de sinais e da realidade surda. São Paulo: Parábola Editorial, 2009.

GÓES, M.C.R. Linguagem, surdez e educação. 2. ed. Campinas: Autores Associados, 1999.

HINDE, R. A. Relationships: a dialectical perspective. London: Psychology Press, 1997.

. Towards understanding relationships: dynamic stability. In: BATESON, P. P. G.;

HINDE, R. A. Growing points in ethology. London: Cambridge University Press, 1976. p. 451-480.

LACERDA, C. B. F. O que dizem/sentem alunos participantes de uma experiência de inclusão escolar com aluno surdo. Rev. Bras. Ed. Esp., Marília, v.13, n.2, p.257-280, 2007.

MARCHESI, A. Comunicação, linguagem e pensamento das crianças surdas. In: COLL, C.; PALACIOS, J.; MARCHESI, A. (Org.). Desenvolvimento psicológico e educação: necessidades educativas especiais e aprendizagem escolar. Porto Alegre: Artes Médicas, 1995. v.3. p.198-214.

MARIN, C. R.; GÓES, M. C. R. A experiência de pessoas surdas em esferas de atividade do cotidiano. Cad. Cedes, Campinas, v.26, n.69, p.231-249, 2006.

OLIVEIRA, A. A. S. O conceito de deficiência em discussão: representações sociais de professores especializados. Rev. Bras. Ed. Esp., Marília, v.10, n.1, p. 59-74, 2004. 
PERLIN, G. T. Identidades surdas. In: SKLIAR, C. (Org.). A surdez: um olhar sobre as diferenças. 3. ed. Porto Alegre: Editora Mediação, 2005. p.51-74.

QUADROS, R. M.; KARNOPP, L. B. Lingua de Sinais Brasileira: estudos linguísticos. Porto Alegre: Artmed, 2004.

ROCHA, S. M. Antíteses, díades, dicotomias no jogo entre memória e apagamento presentes nas narrativas da história da educação de surdos: um olhar para o Instituto Nacional de Educação de Surdos (1856/1961). 2009. 160f. Tese (Doutorado em Educação), Pontifícia Universidade Católica, Rio de Janeiro, 2009.

SÁ, N. R. L. Cultura, poder e educação de surdos. Manaus: Editora da Universidade Federal do Amazonas, 2002.

SANTANA, A. P.; BERGAMO, A. Cultura e identidade surdas: encruzilhada de lutas sociais e teóricas. Educ. Soc. Campinas, v.26, n.91, p.565-582, 2005.

SILVA, A. B. P.; PEREIRA, M. C. C.; ZANOLLI, M. L. Mães ouvintes com filhos surdos: concepção de surdez e escolha da modalidade de linguagem. Psicologia: Teoria e Pesquisa. Brasília, v. 23, n.3. p.279-286, 2007.

SKLIAR, C. Os estudos surdos em educação: problematizando a normalidade. In: (Org.). A surdez: um olhar sobre as diferenças. 3. ed. Porto Alegre: Editora Mediação, 2005. p.7-32.

VIGOTSKI, L, S. Formação social da mente. São Paulo: Martins Fontes, 1999.

Recebido em: 01/02/2011

Reformulado em: 27/06/2011

Aprovados em: 04/07/2011

Rev. Bras. Ed. Esp., Marília, v.17, n.2, p.305-320, Mai.-Ago., 2011 
LOPES, M. A. C.; LEITE, L. P. 